\title{
Exploration on Low-carbon Travel and Establishment of Low-carbon Tourist Attractions
}

\author{
Mintian Li, Shiying Yang \\ Department of Economic Management, Hebei College of Science and Technology, Hebei, Baoding, \\ 071000, China
}

Keywords: Low-carbon travel, Low-carbon tourist attractions, Establishment

\begin{abstract}
The development of tourist industry has inseparable relationship with environment. With the constant development of tourist industry, environmental issue in China has gradually entered the view of the public. However, the development of tourist industry highlights its advantage of low-carbon emission from another perspective. Tourist attractions play a vital role in tourist industry. They can drive the development of tourist industry and develop low-carbon travel. This has important functions for environment. According to the current situation of low-carbon travel, China has very few researches on low-carbon travel and most researches remain in general framework and do not have substantial development. To achieve efficient and rapid development of tourist industry, it is required to conduct low-carbon transformation. This paper analyzes relevant concepts of low-carbon tourist attractions, significance of the establishment of low-carbon tourist attractions, their construction system and benefits and summarizes countermeasures for establishing low-carbon tourist attractions.
\end{abstract}

\section{Introduction}

Low-carbon travel is the development goal of tourist industry as well as an irresistible trend of world tourism. Under the current environment of low-carbon life, low-carbon travel plays a vital role in tourist industry. In the current stage, most people like tourism. Under the pressure of work and life, they are eager to relax themselves, return to nature, enter the open and rustic environment and feel the joy brought by nature.

\section{Relevant concepts of low-carbon travel and low-carbon tourist attractions}

Low-carbon travel. Low-carbon travel is a new way of tourism development in which greater tourism economy, quality and environmental benefits are achieved with the application of low-carbon technologies. It can be said that low-carbon travel is a travel mode with the reduction of carbon dioxide emission. The main purpose of low-carbon travel is to reduce carbon emission. It not only advocates a tourism idea, but also undertakes the responsibility of saving the earth.

Low-carbon tourist attractions. China has pointed out in Tourist Region Quality Grading and Evaluation Standard that tourist attractions are space mainly involving tourism as well as independent management districts providing travel services. They have many functions such as relaxation on holidays and visiting and traveling. Such management districts have correspondingly scope, e.g. tourist areas such as cultural museum, tourist holiday zone, theme park, geological park, zoo and amusement park. It can be said that tourist attractions are independent regions meeting the need of relaxation on holidays of tourists through certain objects. Low-carbon tourist attractions are independent regions meeting the need of relaxation on holidays of tourists with low-carbon operation mode based on tourist attraction. The main objective is to transform traditional scenic spots into low-carbon scenic spots and then promote the development of tourist attractions. In general, low-carbon tourist attractions can be divided into two categories - natural and humanistic ones, as shown in fig.1. 


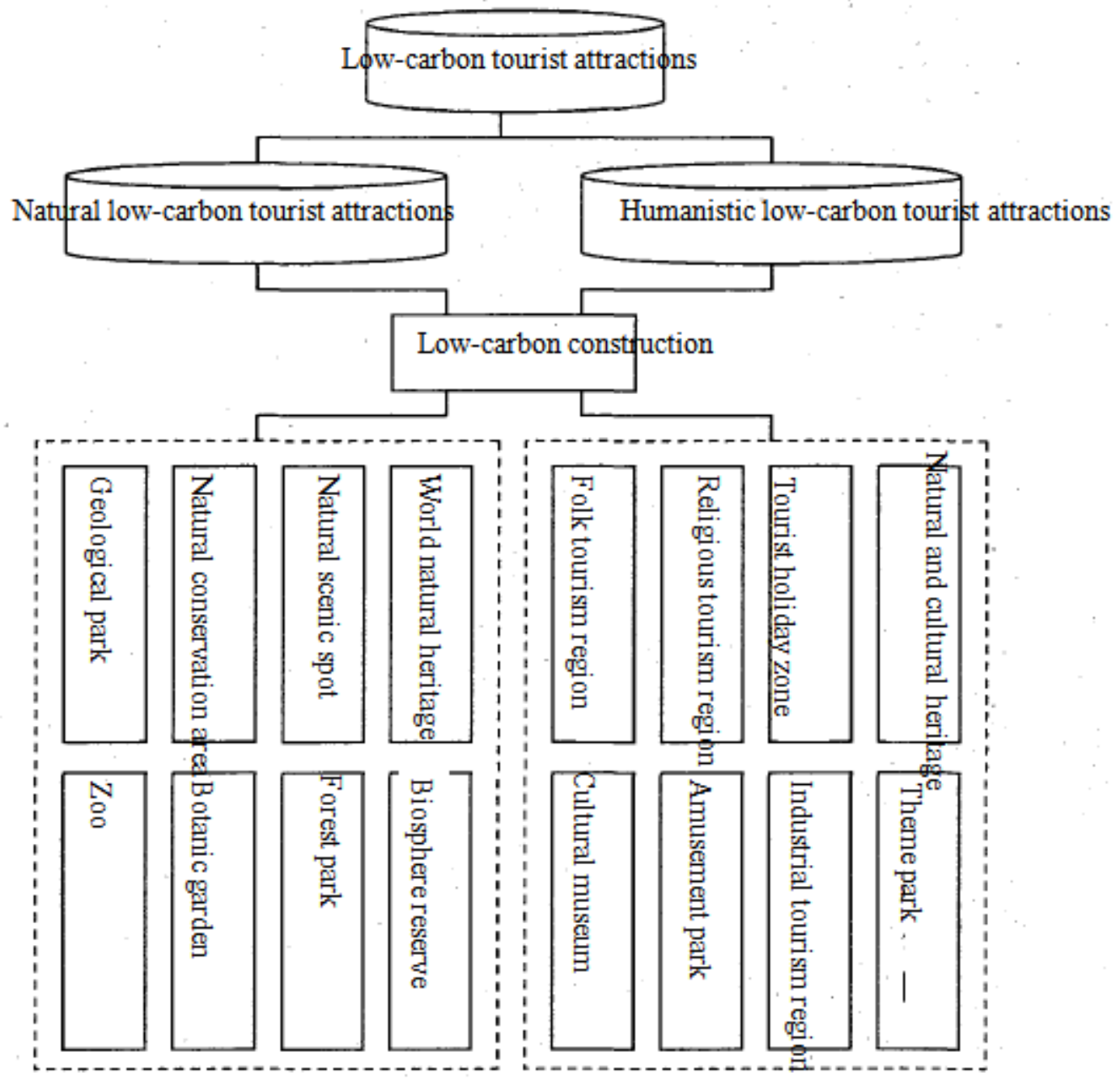

Fig.1. Types of low-carbon tourist attractions

\section{Significance of establishment of low-carbon tourist attractions}

Meet innovation rules of tourist attraction development. In the development process of tourist attractions, the establishment of low-carbon tourist attractions can reform the management mode of scenic spots, integrate their indicators into the existing evaluation, maximize benefits of new technologies and energy and fully meet innovation rules of tourist attraction development.

Impel the masses to develop good low-carbon living habits. In the establishment process of low-carbon tourist attractions, various aspects involved by tourists have a close relationship with low-carbon life. Therefore, we can make tourists fully understand the meaning of low carbon, learn to save resources and protect the surrounding environment and train their habits of ecological civilization through publicity.

Low-carbon tourist attractions are the integrated version of low-carbon travel system. Low-carbon travel form plays an important role in the tourism in the whole world. Therefore, only with the support of the government and society can we establish low-carbon tourist attractions and promote their sustainable development.

\section{Construction system of low-carbon tourist attractions}

Management system. The construction of low-carbon tourist attractions requires the support of various advanced technologies and the state. To guarantee the smooth construction of low-carbon tourist attractions, it is required to establish corresponding system: establish policy management 
system of low-carbon travel in which the government, enterprises and the society should be included; follow four principles - first, master essential requirements of the development of low-carbon travel so as to promote the construction of relevant law of the state; second, establish effective planning policy and complete economic policy according to the demand of low-carbon travel development so as to promote the comprehensive development of low-carbon travel. Third, establish educational policy of low-carbon travel and transfer relevant information of low-carbon travel to tourists so as to allow them to have a comprehensive understanding of low-carbon travel and promote its sustainable development; Forth, improve tourism management policy, revise original tourism management policy, highlight the development concept of low-carbon travel and promote standardized management of low-carbon tourist industry. While following four principles above, it is also required to train tourism workers, make them fully understand low-carbon knowledge, improve their environmental protection awareness and lay a solid foundation for rapid development of low-carbon travel.

Hardware facility system. Hardware facilities of tourist attractions play an important role in tourism development. Hardware facility system of tourist attractions mainly includes tourism energy supply system, tourism building system and tourism traffic system etc. First, it is required to transform tourist attraction energy supply system. Equipment in tourist attractions can be transformed through the utilization of renewable resources; energy utilization system can be subject to low-carbon transformation through low-carbon technologies such as coal water slurry and coal gasification; or low-carbon products can be directly used in tourist attractions. Second, tourism building system should be subject to low-carbon improvement. It is required to reduce the use of fossil energy to the greatest extent and meanwhile use skilled and environmentally friendly materials or plant more green plants to improve the surrounding environment. Moreover, attention should be paid to the selection of building materials in tourist attractions and the coordination with the overall style of tourist attractions. Meanwhile, local materials can be used and foreign matters can be reduced so as to prevent materials such as cement or concrete from damage. Finally, tourism traffic system should be subject to low-carbon improvement. With the constant development of tourist industry, transportation equipment becomes a necessary condition of tourism development. Tourist attractions should allow tourists to fully experience the purpose of tourism and relax themselves while guaranteeing the safety and rapidness of traffic system. Low-carbon traffic system construction is generally divided into the construction of low-carbon roads in tourist attractions, the construction of low-carbon parking lot and the construction of low-carbon means of transport. Low-carbon roads include roadway, footpath and special traffic road. Some gravels or cobblestones can be paved on footpath; lawn bricks can be paved on the ground of parking lot; battery cart or bicycles can be provided in tourist attractions for the purpose of reducing carbon emission and promoting the development of tourist attractions.

Tourism product system. The following should be met in the construction of low-carbon tourist attraction products: first, it is required to improve the use ratio of resources and energy; second, save resources and energy and develop new technologies; finally, guarantee the lowest carbon emission of products in each link. During the establishment of low-carbon tourist attraction products, objects and tourist attraction image attracting tourists should be produced. A low-carbon tourist activity project can be implemented, e.g. activities of walk instead of driving, planting and reward for garbage collection. Low-carbon travel souvenirs can be provided. It' $s$ worth noting that the setting of low-carbon travel souvenirs should follow the principle of local materials and packaging simplification so as to further reduce carbon emission.

Daily maintenance. First, recreational and traffic facilities should be examined at any time. Cleaning work should be guaranteed under the premise of facility safety. Problems found should be solved in time. Second, it is required to maintain facilities and equipment periodically, examine their running situation, adjust loose parts and components, replace aged parts and components and test circuit condition. Then, key parts of facilities and equipment should be examined and controlled. Finally, equipment that cannot run should be repaired. It is required to improve the technology of maintenance personnel, guarantee the quality of maintenance, handle any problem in time to avoid 
influencing tourists, guarantee the use safety of facilities and equipment and make a report in time after the completion of maintenance.

\section{Benefits of low-carbon tourist attractions}

\section{Economic benefit.}

Connected economic benefit

Tourist industry is an industry with strong relevance. Its development will definitely drive the development of many industries. Therefore, the construction of low-carbon tourist attractions will inevitably increase economic benefits of enterprises and relevant industries.

Economic benefit of resource saving

As is known to all, the main objective of construction of low-carbon tourist attractions is low carbon emission, i.e. energy and resource saving. Energy and resource saving can bring substantial economic benefits.

Economic benefit of new image

The establishment of low-carbon tourism can raise the concern of the masses and attract a lot of tourists. Therefore, it will bring great economic benefits to tourist attractions.

\section{Environmental benefit.}

The construction of low-carbon tourist attraction is the most important constituent part of low-carbon economic development. Its utmost purpose is energy saving and emission reduction. It can save resources and energy, reduce environmental pollution and then alleviate the global climate warming trend.

\section{Social benefit.}

First, it can solve energy problems. Difficulties of low-carbon tourist attractions include energy saving and emission reduction and the reduction of energy consumption. Under such environment, the government will definitely strengthen the research and development of energy so as to alleviate the demand for energy, consolidate Chinese energy safety and reduce the waste of energy and resources to a certain extent. Second, the construction of low-carbon tourist attraction can optimize structural adjustment of tourist industry and achieve the purpose of saving resources. Third, it can provide employment opportunities for talents not getting a job in the society. As the construction of low-carbon tourist attraction is a new topic, a lot of talents are required as support. This is helpful for talents not getting a job to a certain extent. Forth, the construction of low-carbon tourist attraction can promote the development of tourist industry, promote low-carbon development of transportation industry, construction industry and business indirectly and further entry into conservation-minded society, improve the international competitiveness of China and drive the development of its national economy ${ }^{[2]}$.

\section{Countermeasures for establishment of low-carbon tourist attractions}

First, it is required to improve low-carbon travel mechanism, follow the guidance of the government and establish incentive and support system. In the process of establishing the system, the government should conduct analysis according to the practical situation of low-carbon environmental protection, support the smooth implementation of low-carbon travel in funds and spirit, cultivate the ability of technical innovation, strengthen the improvement of tourism based on energy saving and emission reduction, set up demonstration points of low-carbon travel and guarantee the maximum economic benefit of low-carbon travel. Second, plan and develop low-carbon tourist attractions scientifically and reasonably, specify development concepts of low-carbon economy, attach importance to the development of surrounding environment, establish low-carbon system, allocate relevant facilities such as buildings in tourist attractions to tourist projects reasonably so as to promote sustainable development of low-carbon tourism and meanwhile improve evaluation system so as to use energy saving and emission reduction effectively. Finally, plan tourist attractions scientifically and reasonably. Previous tourist attractions are not advanced in technology and have problems in energy saving and emission reduction. Management personnel of tourist attractions pay 
excessive attention to the development of tourism hardware and less attention to human and natural factors. This seriously hinders the development of tourist attractions to a certain extent. Therefore, it is necessary to pay attention to the relation between people and the environment and nature during the planning of tourist attractions, establish an environment suitable for the living of tourists and create a good atmosphere ${ }^{[3]}$.Finally, abide by development elements of low-carbon travel strictly, mainly manifested in two aspects: first, improve relevant facilities of low-carbon travel, provide services for tourists with technologies of energy saving and emission reduction, improve services for tourists in road, environment, catering, recreation and accommodation, use means of transportation such as sightseeing bikes and regenerative resources to reduce resource waste. Second, low-carbon tourist consumption ways should be promoted. Tourists can minimize their carbon emission, collect garbage produced during travel consciously and meanwhile walk for sightseeing so as to save energy and reduce emission. Third, develop characteristic tourist projects. Tourist attractions should make a plan scientifically and reasonably according to their own situations and gain maximum economic benefits with low carbon costs. Forth, create low-carbon travel experience environment. It is required to allow tourists to communicate with nature as much as possible and get more in spirit in low-carbon tourism. Though such practice will not gain the support of the majority, this good wish will be achieved soon.

\section{Conclusion}

Currently, Chinese low-carbon travel is developing. The government must enhance the understanding of low-carbon travel and low-carbon tourist attractions so as to reduce environmental pollution, protect resources on the earth and then promote the development of tourist industry and the society.

\section{References}

[1] Huang Wensheng. Discussions on Establishment of Low-carbon Travel and Low-carbon Tourist Attractions. Ecological Economy, 2010(11):100-102.

[2] Zhu Yuxia. Establishment of Environmentally Friendly Tourist Hotels and Low-carbon Tourist Attractions. Journal of Taiyuan Urban Vocational and Technical College, 2014(8):59-60.

[3] Zeng Manqiong. Discussions on Establishment of Tourist Attractions under Low-carbon Economy. Journal of Harbin Vocational and Technical College, 2010(4):109-110. 